\title{
The Significance of Informal Logic for Philosophy
}

\section{David Hitchcock}

McMaster University

\begin{abstract}
Informal logic is a new sub-diseipline of philosophy, roughly definable as the philosophy of argument. Contributors have challenged the traditional concept of an argument as a premiss-conclusion complex. in favour of speech-act, functional and dialogical conceptions; theyhave identified as additional components warrants, modal qualifiers, rebuttals, and a dialectical tier. They have objected that "soundness" is neither necessary nor sufficient for a good argument. Alternative proposals include acceptability. relevance and sufficiency of the premisses; conformity to a valid argument schema: conformity to rules for discussion aimed at rational resolution of a dispute. Informal logic is a significant part of philosophy.
\end{abstract}

\begin{abstract}
Résumé: La logique non formelle est une nouvelle sous-discipline de la philosophie qui se definit approximativement comme la philosophie de l=argument. Les collaborateurs et les collaboratrices mettent en question la notion traditionnelle selon laquelle le tout $d=u n$ argument sont ses prémisses et sa conclusion. On propose de complèter cette description en employant des conceptions fonctionnelle et dialogique, et des notions des actes du langage, et en identifiant $d=$ autres parties composantes telles que des lois de passage. des guaranties. des reserves, et des aspects dialectiques. On avane que la vérité des prémisses et la validité déductive ne sont ni nécessaires et ni suffisantes pour qu=un argument soit probant. On propose au lieu $I=$ acceptabilite. la pertinence, et la suffisance des prémisses. la conformité à des schemes argumentatifs valides et à des règles discursives visant la résolution rationnelle des desaccords. La logique non formelle est une consituante importante de la philosophie.
\end{abstract}

Keywords: informal logic, philosophy, argument, evaluation, dialogue, acceptability. relevance, sufficiency, argumentation schema, fallacies.

Informal logic is a new sub-discipline within philosophy. Its subject-matter is roughly defined by a set of questions which Ralph Johnson and Tony Blair of the University of Windsor set out under 13 headings in an appendix to their opening address at the First International Symposium on Informal Logic, held in Windsor in June 1978. (Johnson and Blair, 1980: 25-26) Among the key questions in their list are the following:

- What are the criteria to be invoked in logical criticism?

- What is the nature of argument?

- What is the nature of fallacy? 
- How should fallacies be classified?

- Are the validity/soundness criteria of evaluation [sc. of arguments] inappropriate or outmoded? If so, what should replace them?

- Can principles be formulated that assign the responsibilities of give-andtake in argumentation?

- What different kinds of assumptions can be distinguished in argumentation? How are missing premisses to be identified and formulated?

- How does the context of argumentation affect its meaning and interpretation?

In sum, informal logic is the study of arguments.

Of course, the questions investigated by informal logic are not new; Aristotle already addressed many of them. What is new is the central focus on argumentation in natural language, as an interpersonal, social, purposive practice. What is new too, at least in comparison to other philosophical investigations of arguments and reasoning in the last 100 years, is the skepticism about the value of formal logic as a tool for analyzing and evaluating natural-language arguments. This skepticism is implicit in the very name "informal logic", with all its unfortunate connotations of sloppiness and lack of rigour. What is the significance of this new sub-discipline for philosophy?

Reasoning and argument are central to the practice of philosophy, and also central to its subject-matter, in particular to its focus on knowledge. As a subdiscipline devoted to the theoretical study of reasoning and argument, informal logic has the potential to make a substantial contribution to philosophy in general. I shall consider these potential contributions under two headings: the concept of argument and the evaluation of arguments. I ignore another equally substantial and equally important subject of investigation within informal logic: the theory of fallacies. And I make no attempt to be comprehensive in the contributions I mention; in fact, I am acutely conscious of having failed to mention several important contributions on the topics I discuss.

\section{The concept of argument}

What is an argument? Traditionally an argument is defined as a system composed of premisses and conclusion, a definition which goes back to the early Stoics of the third century BCE. (Diogenes Laertius VII.45, 76 = SVF 11 235, Crinis fr. 5) The premisses and conclusion may be spoken, written or thought. By the conclusion is meant that which is inferred from, or is presented as following from, the premisses. By the premisses are meant the components from which the conclusion is inferred, or presented as following. Thus an argument is at heart a piece of reasoning in which something is inferred from, or presented as following from, some other thing(s). Using a variant terminology from that of "premiss" and "conclusion", one can sum up by saying that on this traditional conception an argument is a claim-reason complex. 
The conception of an argument as a claim-reason complex has come under sustained attack in the informal logic tradition of the last 20 years, on a number of grounds.

\section{1.l. Arguing as a speech act}

First, it conceives of an argument as a certain kind of product. But any product is the result of an act of production which is prior to the product. In this case, the act is an act of arguing, a certain kind of speech act which deserves investigation to determine its specific characteristics. Arguing turns out to be a complex illocutionary act, whose typical performance can be given the usual Searlian analysis (Searle 1969 ) in terms of propositional content conditions, essential conditions, preparatory conditions, and sincerity conditions. Among the preparatory conditions for felicitous arguing, for example, are that (the arguer believes that) the intended audience does not already accept the conclusion, and that (the arguer believes that) the intended audience will accept the premisses (van Eemeren and Grootendorst, 1984: 44). In addition to being an illocutionary act with distinctive felicity conditions, arguing typically has a distinctive intended perlocutionary effect, that of persuading the arguer's intended audience to accept the conclusion on the basis of the asserted premisses.

\subsection{The function(s) of argument}

Second, even if we treat arguments as products rather than as speech acts, the traditional conception of argument as a system composed of premisses and conclusion ignores the purpose for which such systems are created. This purpose, some claim, is rational persuasion (Johnson, 1996: 105). Others (e.g., Ennis, 1997: 6) speak of its purpose as that of proving or establishing the conclusion. Argument is an alternative to coercion on the one hand, and to irrational or non-rational persuasion on the other. Construed this way, the practice of argument has an important place in a democratic social and political system, in which all those affected have a voice in decisions which affect them; ideally those decisions are reached as a result of informed and vigorous discussion and debate. The practice of argument also has an important place in personal decisions about what to believe and what to do, since such decisions are likely to be wiser if reached on the basis of careful consideration of relevant arguments than if reached some other way.

A more pluralistic approach to argument treats rational persuasion of the audience, or establishing the conclusion, as only one possible purpose of argument. Claim-reason complexes can serve the functions of articulating our thought processes to ourselves as we work out the solution to a problem, explaining to somebody else why we hold a certain belief or undertake a certain course of action, giving a causal or logical explanation of some already acknowledged general truth, working out the consequences of a hypothesis in order to design an experimental 
test of it, exposing to another person an internal inconsistency in their beliefs, and so forth. It is an open question whether these functions are parasitic on the usually privileged function of rational persuasion or proof.

\subsection{The macrostructure of arguments}

Third, there is an influential current in informal logic, stemming from Stephen Toulmin's The Uses of Argument (1958), which holds that there are more components to an argument as product than just the claim (or conclusion) and the reasons (or premisses). Toulmin uses the word "claim" for the conclusion and the word "data" or "grounds" for the premisses. But he identifies four other components of the system, of which three are particularly noteworthy.

What Toulmin calls the "warrant" is the arguer's answer to the question: How do you get from what you have to go on (your data or grounds) to your claim? The answer, which is always unstated in the original argument, will have the form of a generalized conditional statement, perhaps with some modal qualifier. But its function is that of a rule of inference, licensing the making of the claim on the basis of the arguer's data or grounds. Toulmin uses the hackneyed but now familiar example of the argument, "Harry was born in Bermuda, so he is probably a British subject". Asked how this conclusion is obtained, the arguer will say, "Generally, a person born in Bermuda will be a British subject." Toulmin's concept of a warrant explains very well a feature common to virtually all natural-language argument: it is not formally valid. It is rather, as I would say, "enthymematically valid" or "materially valid". That is, it is valid in virtue of a rule of inference which is not purely formal, which has some content. Such rules may be grounded semantically, scientifically, legally, or in a myriad other ways.

A second component of many arguments is what Toulmin calls the "modal qualifier". It occurs in his example of Harry's citizenship in the form of the words "probably" qualifying the conclusion and the word "generally" in the warrant. Such words or phrases indicate the force of the warrant, whether it holds universally (indicated by "must"), usually (indicated by "generally" or "probably"), presumptively (indicated by "presumably") or sometimes (indicated by "possibly").

A third novel component in Toulmin's analysis is what he calls "rebuttals". Rebuttals are a peculiarity of arguments whose warrant justifies only a presumption that the conclusion is true. Such presumptions are subject to rebuttal, by showing that some exception-making condition obtains. Pollock (1990: 79) has pointed out that, in addition to such rebuttals, there can be what he calls "undercutting defeaters", which attack the connection between a prima facie reason and a conclusion. In Toulmin's example, the presumption that someone born in Bermuda is a British subject might be rebutted by showing that neither of his parents was a British subject. Such a rebuttal might be incorporated in the original argument in the form of an "unless" clause qualifying the conclusion: Harry is a British citizen, unless neither of his parents was a British subject. 


\subsection{Argument as dialogical exchange}

Fourth, some theorists of argument take conversational argument as primary, and assimilate other forms of argument to this primary form. An argument in this sense is a conversational exchange. Different forms of argumentative conversational exchange are conceivable. What contemporary speech communication theorists call a "confrontation sequence" is an attempt by one interlocutor to refute the other's thesis by eliciting admissions which generate some absurdity: in short, Socratic refutation, called in the middle ages the "obligation game". What C. L, Hamblin in his classic work, Fallacies (1970), called a "why-because" game is an attempt by one interlocutor to elicit a satisfactory justification of an initial claim made by the other interlocutor. Paul Lorenzen formulated intuitionistic logic as a set of strip rules which enable one interlocutor to break down the commitments of another interlocutor in order to show that they entailed some proposition; Lorenzen's work has been developed by Else Barth and Erik Krabbe (1982). Conversational argument can be studied empirically, in an effort to detect regularities in its occurrence and structure; an influential theory (Jackson \& Jacobs, 1980, 1981; Jacobs \& Jackson, 1981, 1982) holds that conversational argument is a systematic method for regulating disagreement. It can also be studied formally, by setting up mathematically well-defined systems in which it is possible to determine, for example, whether a player in a certain situation has a winning strategy; Douglas Walton and Erik Krabbe have made important contributions in this direction (e.g. Walton \& Krabbe, 1995). And it can be studied quasi-empirically, by setting up a system of rules which function as an ideal model for a critical discussion, and interpreting actual arguments, even non-conversational arguments, in the light of this ideal model (van Eemeren and Grootendorst, 1984, 1992a).

Even theorists who take arguments to be primarily monological rather than dialogical (e.g., Johnson, 1996) wish to add to the structural tier of premisses and conclusion what they call a "dialectical tier", in which the arguer anticipates objections to the premisses and inferential links of the structural tier. The dialectical tier is a part of the argument, because the argument is what serves the function of rational persuasion, and responding to anticipated objections is a constitutive part of an attempt at rational persuasion.

\section{The evaluation of arguments}

So much on the analysis of arguments. A second major focus of informal logic is the evaluation of arguments. It may seem surprising that there is no consensus within informal logic, or outside it, on what is to count as a good argument.

\subsection{The rejection of soundness}

There is however wide agreement within informal logic on the inadequacy of one conception of a good argument which is influential in contemporary philosophy. 1 
refer to what is called a "sound argument": a formally valid argument with true premisses. (See for example Schumm's entry on "soundness" in the $1995 \mathrm{Cam}$ bridge Dictionary of Philosophy, 756.) There are obvious counter-examples to the hypothesis that an argument is good if and only if it is sound in this technical sense. We can see that some arguments which we take to be good are not sound by reflecting on examples of perfectly acceptable arguments whose premisses are not all true, or whose inferential step is not deductively valid. For example, quantitative reasoning about the real world often relies on estimates or assumptions which are conceded to be idealizations or mere guesses; the cogency of such reasoning can be tested by seeing if the conclusion is much different when the assumptions are changed in technical terminology, whether the conclusion is robust. And some arguments which we regard as good have, in Toulmin's terminology, modally qualified warrants which license only a probable or presumptive conclusion; a simple example is an argument from generally reliable authority, e.g. that it will probably rain today, because this morning's forecast said there was a $90 \%$ probability of precipitation. (This latter sort of counter-example would not be accepted, however, by all researchers in informal logic; there are defenders of what is stigmatized as "deductive chauvinism", the view that all good arguments are deductively valid. Even such deductive chauvinists, however, are likely to recognize that deductive validity encompasses more than formal validity; an argument like "Jones is a bachelor, so Jones is male" is deductively valid, in the sense that the meaning of its components rules out the possibility that its premiss is true and its conclusion false, even though it is not formally valid.)

There are also counter-examples in the other direction, sound arguments which our critical practice regards as no good. For example, any proposition follows necessarily from itself. Hence an argument of the form " $p$, therefore $p$ " is deductively valid, and indeed formally valid. But the truth of $p$ does not make this a good argument. Repetition of this sort is a highly effective rhetorical device, but it is of no value at all as proof. If the truth of $p$ is already known to the audience, the argument is useless; if the truth of $p$ is in question, the argument is of no help in providing the audience with reasons for thinking that it is true.

\subsection{A functional approach}

In generating counterexamples to the thesis that arguments are good if and only if they are sound, we appeal partly to our current "naive" (i.e., supposedly theoretically untutored) critical practice in assessing arguments. But we appeal also to the supposed function of arguments, e.g., the function of rational persuasion. This functional approach provides an important clue, I think, to the development of criteria for evaluating arguments. In general, if to belong to a certain kind is to have a certain function, then an individual is a good member of that kind if and only if it has the characteristics that enable it to perform that function well. A good paring-knife is one which has the characteristics that enable it to pare well. Just 
so, a good argument is one which has the characteristics that enable it to perform well whatever function arguments serve. If different arguments serve different functions, then the criteria for evaluating them may well be different too, varying according to the function of the argument under consideration. This perspective enables us to understand some of the divergence among informal logicians in the criteria they propose for the evaluation of arguments.

\subsection{Acceptability, relevance, sufficiency}

A popular set of criteria, due originally to Johnson and Blair (1977), is the triad of acceptability, relevance and sufficiency. Each premiss must be acceptable. Each premiss must be relevant to the conclusion. And the premisses must be jointly sufficient. Acceptability is here relative to the particular evaluator, or to the particular audience for whom the evaluator is judging the worth of the argument. It refers not to the mere fact that the evaluator or audience accepts the premiss, but to its being reasonable for the evaluator or audience to accept the premiss, whether or not they in fact do so. Thus a premiss can be acceptable to a particular person, even though the person does not in fact accept it. Further it can be acceptable even if it is false; a false premiss is acceptable to someone if that person has good reason to accept it.

The criterion of relevance is controversial. John Woods (1994), among others, has severely attacked attempts to construe relevance as a semantic relation, expressed by some such phrase as "contributing to the truth of". It seems more defensible to construe relevance as a pragmatic concept, expressed by some such phrase as "contributing to the (assumed) goal in the context". However construed, it is doubtful whether relevance of each premiss is a necessary condition for a good argument. To say so is to imply that a good argument can be turned into a bad one by adding an irrelevant premiss. And this does not seem like an acceptable consequence. The argument may become inelegant, or burdened with a superfluity, but in typical cases adding an irrelevant premiss will leave the argument still capable of fulfilling its function.

The criterion of sufficiency is true but schematic. It is of course true that a good argument must be such that its premisses, if true, would provide enough support to the conclusion. By definition of "enough", if they did not provide enough support, the argument would not be doing its job. But how much is enough, in what circumstances?

Toulmin's concept of a warrant can provide the basis for a more specific approach. An argument which is supposed to prove its conclusion definitively, or beyond a reasonable doubt, needs an exceptionless, or almost exceptionless, warrant. One which is supposed merely to make its conclusion probable, or to establish a presumption, or to register it as a hypothesis worth continued investigation, needs respectively warrants that are usually true, that are presumptively true, or that are sometimes true. 


\subsection{Argument schemata}

This approach using modal qualifiers is more substantive, but still schematic. There is some empirical evidence from cognitive psychology that human beings generally do not reason at such a high level of abstraction (Nisbett, Fong, Lehman \& Cheng, 1987). When they reason deductively, for example, they make mistakes when required to apply such abstract forms as modus ponens and modus tollens. But they are virtually $100 \%$ accurate when they apply to familiar contexts such specifications of these abstract forms as permission schemata ("if condition $\mathrm{A}$ is met, then you may do B"), obligation schemata ("if condition A is met, then you must do B") or causal schemata ("if A occurs, then B will occur as a result").

What seems to be appropriate, then, is to develop a set of argumentation schemata, expressed at the middle level of abstraction at which human beings typically do their thinking. There might be an argumentation schema, for example, for reasoning from the results of a controlled experiment. There is a growing literature, both in North America and in Europe, on such argumentation schemata; see for example Kienpointner (1992) and Grennan (1996). Some researchers have developed dozens of them, each with its own pattern and set of validity conditions.

\subsection{The fallacies approach}

Finally, one approach to the evaluation of arguments is through a search for fallacies. Outsiders often identify informal logic with the study of the informal fallacies, which are recognized to be something not covered by formal logic, and to be faults which arguments do in fact commit. Many researchers within informal logic, however, are skeptical of a fallacies approach to the evaluation of arguments. In the first place, the traditional fallacy labels, such as ad hominem or appeal to authority (Locke's ad verecundiam), describe forms of argument which are often perfectly reasonable. Quite a lot of careful and valuable research has been done in informal logic on identifying the conditions under which a given argumentative move is legitimate and the conditions under which it is fallacious. Secondly, from a pedagogical point of view, organizing the teaching of practical skills of argument evaluation around a taxonomy of fallacies encourages unduly negative attitudes to argument, tends to substitute name-calling for substantive engagement with the content of an argument, and runs into the problem that the exercise of pinning a particular fallacy label on a particular argument is fraught with controversy, even among experts.

Approaches to fallacies tend, as one would expect, to reflect the general approach to the understanding of argument. Those who take a dialectical or conversational approach tend to have a wider conception of the types of mistakes that arguments can display. One persuasive analysis of the abusive ad hominem, for example, takes it as having nothing to do with the adequacy of a premiss or sufficiency of an inferential link, but rather as an illegitimate move at the confrontation 
stage of a critical discussion, a move which tries to undermine the right of one of the discussants to put forward and defend their point of view (van Eemeren \& Grootendorst 1992b). When we look at actual cases of abusive ad hominem, we find that they fit this analysis better than any analysis in terms of a arguments as claim-reason complexes.

\section{Conclusion}

What I hope to have shown through this brief selective review is that informal logic investigates many questions which are of great philosophical interest and importance. Further, these questions are inter-linked, and form the subject-matter of a sub-discipline which has some integrity, although of course it has links to other branches of philosophy, as well as to such other disciplines as speech communication, psychology and linguistics. No other sub-discipline of philosophy studies these questions thematically. Informal logic, then, is a part, and an important part, of philosophy.

\section{References}

Barth, Else, \& Erik C. W. Krabbe. 1982. From Axiom to Dialogue: A philosophical study of logics and argumentation. New York: Walter de Gruyter.

Diogenes Laertius. 1925. Lives and Opinions of Eminent Philosophers, with an English translation by R.D. Hicks. 2 vols. Cambridge : Harvard University Press, 1925.

Eemeren, Frans H. van, \& Rob Grootendorst. 1984. Speech Acts in Argumentative Discussions: A theoretical model for the analysis of discussions directed towards solving conflicts of opinion. Dordrecht/Cinnaminson: Foris.

Eemeren, Frans H. van, \& Rob Grootendorst. 1992a. Argumentation, Communication and Fallacies. Hillsdale, NJ: Lawrence Erlbaum.

Eemeren, Frans H. van, \& Rob Grootendorst. 1992b. Relevance reviewed: the case of argumentum ad hominem. Argumentation 6, 141-159.

Ennis, Robert. 1997. Critical Thinking. Upper Saddle River, NJ: Prentice-Hall.

Grennan; Wayne. 1996. Informal Logic: Issues and Approaches. Montreal: McGillQueen's University Press.

Hamblin, C. L. 1970. Fallacies. London: Methuen.

Jackson, Sally, \& Scott Jacobs. 1980. Structure of conversational argument: pragmatic bases for the enthymeme. Quarterly Journal of Speech 66, 251-265.

Jackson, Sally, \& Scott Jacobs. 1981. The collaborative production of proposals in conversational argument and persuasion: A study of disagreement regulation. Journal of the American Forensic Association 18, 77-90.

Jacobs, Scott, \& Sally Jackson. 1981. Argument as a natural category: The routine grounds for arguing in conversation. Western Journal of Speech Communication $45,118-132$. 
Jacobs, Scott, \& Sally Jackson. 1982. Conversational argument: A discourse analytic approach. In J. R. Cox \& C.A. Willard (eds.), Advances in Argumentation Theory and Research (Carbondale: University of Southern Illinois), 205-237.

Johnson, Ralph H. 1996. The Rise of Informal Logic. Newport News, VA: Vale Press. Johnson, Ralph H., \& J. Anthony Blair. 1977. Logical Self-Defense. Toronto: McGraw Hill-Ryerson.

Johnson, Ralph H., \& J. Anthony Blair. 1980. The recent development of informal logic. In J. Anthony Blair and Ralph H. Johnson, eds., Informal Logic: The First International Symposium (Inverness, CA: Edgepress), 3-28.

Kienpointner, Manfred. 1992. Alltagslogik. Stuttgart: Frommann-Holzboog.

Nisbett, Richard E., Geoffrey T. Fong, Darrin R. Lehman \& Patricia W. Cheng. 1987. Teaching reasoning. Science 238, 625-631.

Pollock, John L. 1990. Nomic Probability and the Foundations of Induction. New York: Oxford University Press.

Schumm, George F. 1995. Soundness. In Robert Audi (ed.), The Cambridge Dictionary of Philosophy (Cambridge: Cambridge University Press), 756.

Searle, John. 1969. Speech Acts: An Essay in the Philosophy of Language. Cambridge: Cambridge University Press.

SVF: See Von Arnim, Johann.

Toulmin, Stephen. 1958. The Uses of Argument. Cambridge: Cambridge University Press. Von Arnim, Johann. 1968. Stoicorum Veterum Fragmenta [SVF]. 4 vols. Stuttgart: Teubner. First published 1905-1924.

Walton, Douglas N., \& Erik C. W. Krabbe. 1995. Commitment in Dialogue: Basic Concepts of Interpersonal Reasoning. Albany, NY: State University of New York Press.

Woods, John. 1994. Sunny prospects for relevance? In Ralph H. Johnson \& J. Anthony Blair, eds., New Essays in Informal Logic (Windsor, ON: Informal Logic), 82-92.

David Hitchcock Department of Philosophy McMaster University Hamilton. Ontario Canada L8S 4 L8 